\title{
MARIE CARDINAL TRADUZIDA: A TRAJETÓRIA INTERNACIONAL DE SEUS ESCRITOS
}

\author{
MARIE CARDINAL IN TRANSLATION: THE INTERNATIONAL JOURNEY OF \\ HER WRITING
}

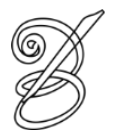

Maitê DIETZE*

Universidade Federal de Santa Catarina, Brasil

\begin{abstract}
Resumo: O artigo apresenta o percurso da obra da escritora francófona Marie Cardinal, a fim de analisar a difusão das traduções de seus livros. Para tanto, essa contribuição se inicia com uma breve contextualização da vida e do trabalho da autora, relatando seus aspectos centrais e discorrendo sobre os eixos discursivos componentes de seus escritos. A seguir, retrata-se o mapeamento das traduções publicadas pelo mundo, considerado como panorama quantitativo que introduz a análise internacional do estado da arte da autora. Partindo desse levantamento, a análise tradutória enfoca o caso do livro mais vendido e traduzido para o maior número de línguas: Les mots pour le dire (1975); analisa-se também a situação de Autrement dit (1977) que, embora seja uma subsequência dessa obra e, portanto, diretamente relacionada a ela, teve repercussões divergentes. Tal análise toma como objeto os paratextos (GÉNETTE, 1987) das traduções para inglês e português dos livros de Cardinal. Observando os dados presentes nos peritextos e epitextos, em nível preliminar e macroestrutural (LAMBERT; VAN GORP, 1985), encontram-se informações indicativas da recepção dos livros na cultura de chegada lusófona e anglófona. Com essa pesquisa, considera-se que a obra de Cardinal constitui uma escrita particularmente maleável, podendo ser interpretada em prismas diversos; cada tradução analisada aponta, através dos paratextos, um direcionamento de leitura para o texto em questão. Supõe-se que projetos de traduções que almejem manter a maleabilidade característica da escritura da autora precisam ter em conta uma avaliação global e equilibrada dos aspectos identificados como fundamentais de seu discurso. O interesse da escritura de Cardinal para âmbitos como a crítica feminista, os estudos culturais e a psicanálise é explícito nos textos originais; pretende-se, enfim, partir desse levantamento históricocrítico para desenvolver novos estudos, aprofundando a pesquisa sobre a contribuição de Cardinal em tais âmbitos, bem como propondo projetos de tradução inéditos e que tenham em vista esses interesses.
\end{abstract}

Palavras-chave: Marie Cardinal. Recepção de Traduções. Crítica de Tradução. Paratextos.

Abstract: This paper introduces a survey through the work of Marie Cardinal, a francophone writer, and aims to analyze the diffusion of the translations of her books. The study begins with a brief review of the author's life and work, exhibiting their main aspects and explaining the discursive axes that compose her writing. Afterward, a mapping of the translations of her works published worldwide is presented, considered as a quantitative overview that introduces the international analysis of the author's state of the art. On the basis of this mapping, the translation analysis focuses on the author's best-selling and most translated book: Les mots pour le dire (1975); it also analyzes the situation of Autrement dit (1977) which, even though it is a sequence of the first and therefore directly connected to it, ended up having very different reverberation. This analysis has as object the paratexts (GÉNETTE, 1987) of the English and Portuguese translations of Cardinal's books. Reviewing the information included in peritexts and epitexts, in preliminary and macrostructural levels (LAMBERT; VAN GORP, 1985), indications of the reception of those books by the lusophone and anglophone target culture were found. Through this research, it is acknowledge that Cardinal's work constitutes a particularly malleable writing, which can be interpreted by several angles; each one of the analyzed translations point out, through the paratexts, a direction to read the text in question. One assumes that translation projects aiming to maintain that malleability, characteristic of the author's writing, must take into account a global and balanced assessment of the aspects identified as central to her discourse. The interest on Cardinal's writing to fields such as feminist critique, cultural studies and psychoanalysis is explicit in the original texts; finally, this historical-critical research is intended to 
be developed by delving into the author's contribution in such areas, as well as proposing new translation projects that address such interests.

Keywords: Marie Cardinal. Reception of Translations. Translation Critique. Paratexts.

RECEBIDO EM: 23 de maio de 2019

ACEITO EM: 17 de julho de 2019

PUBLICADO EM: janeiro 2020 


\section{Introdução}

arie Cardinal (1929-2001) é uma escritora de expressão francesa, conhecida
sobretudo em círculos feministas, psicanalíticos e de estudos culturais. Este artigo
tem por intuito comentar o transcurso dessa escritora pied-noir em outros mundos, conduzida em tradução. Para tanto, após a apresentação do teor do discurso componente da escritura de Cardinal, será observado o discurso sobre e com seus textos, ou seja, os paratextos (GÉNETTE, 1987, p. 8) de alguns trabalhos traduzidos para inglês e português. A análise parte do panorama geral das obras e das traduções, para se aprofundar no exemplo da mais vendida e traduzida, Les mots pour le dire (1975), que conta com traduções em dezessete línguas e mais de 320 mil exemplares vendidos na França, bem como de sua subsequência, Autrement dit (1977); finalmente, atentar-se-á às traduções (in)existentes em língua inglesa e portuguesa, observando seus peritextos (textos que as acompanham paralelamente: capa, prefácio, posfácio etc.) e epitextos (textos sobre as obras, mas fora delas: debates, críticas, entrevistas, correspondências, etc.) de cada tradução (GÉNETTE, 1987, p. 10-11).

Ao desenvolver a análise tradutória dos textos de Cardinal, há possibilidade de realizála em diferentes níveis; aplica-se aqui o modelo descritivo proposto por Lambert e Van Gorp (1985). Tal modelo é estruturado da seguinte forma: a primeira etapa é dedicada ao levantamento e análise de dados preliminares (título, nome do autor e do tradutor, metatexto, etc.); a segunda, examina a macroestrutura do texto (capítulos, estrutura interna da narração, etc.); a última etapa consiste na análise da microestrutura e do contexto sistemático do texto. A observação de cada etapa indica hipóteses sobre o nível seguinte (LAMBERT; VAN GORP, 1985, p. 52-53). O presente artigo analisa o primeiro nível, comentando as informações preliminares situadas em cada tradução, bem como parte do nível macroestrutural, sobretudo o que é expresso em prefácios e posfácios (peritextos) e em artigos de crítica acadêmica (epitextos).

O estudo elaborado através dessa análise dos paratextos expõe que a incursão de Cardinal pelo sistema literário brasileiro foi débil se comparada com o sistema anglófono; tais lacunas, tanto nas traduções das obras quanto em seu estado de arte, impedem o acesso às concepções frutíferas que Cardinal acrescenta a domínios como o psicanalítico, o feminista e os estudos culturais, dadas as particularidades da sua escritura. Finalmente, as discussões presentes são consideradas um levantamento histórico-crítico inicial das vias por onde Cardinal-traduzida transcorreu, proposto a evoluir posteriormente em análises das relações da autora com seus âmbitos de recepção, bem como em análises tradutórias aprofundadas em todos 
os níveis (LAMBERT; VAN GORP, 1985). Tais estudos buscam, além dos aportes teóricotradutórios, revitalizar a literatura da autora e estimular novas traduções de seus livros.

\section{Marie Cardinal: qual discurso a decorre?}

Marie Cardinal nasceu na Argélia, descendente de abastados colonizadores franceses. Como muitos pieds-noirs, Cardinal foi repatriada na ocasião da Guerra de Independência Argelina. Apesar de seu diploma de Filosofia pela Universidade Sorbonne, obtido em 1948, ela nunca trabalha na área; Cardinal leciona francês em Salônica, Lisboa, Viena e Montreal, cidades onde acompanha seu marido, o diretor de cinema Jean-Pierre Rofard. Com a repatriação, na década de 1960, Cardinal passa a viver de sua escrita em Paris, a princípio como escritorafantasma e redatora de artigos em jornais e revistas semanais. Com o advento do tratamento psicanalítico, descobre a escrita como processo de cura e insere-se então entre as escritoras mulheres que guiam a cena literária francesa da época.

Seu primeiro romance, Écoutez la mer (1962), é premiado ${ }^{1}$ em 1963. Dez anos depois, o sucesso alcançado por La clé sur la porte (1972) traz uma adaptação cinematográfica

92 realizada por Yvez Boisset. Contudo, a produção literária de Cardinal só será devidamente reconhecida com o lançamento do romance Les mots pour le dire (1975), no qual a autora narra seu tratamento psicanalítico. Os romances de Cardinal são permeados por acontecimentos pessoais, retomando os mesmos temas e problemáticas, numa espécie de escrita cíclica: ela entrelaça um escrito no outro, ultrapassando os limites do gênero em um sistema de autocitações que possibilita uma leitura global da obra (HALL, 1994, p. 10). A psicanálise é um dos interesses fundamentais nos escritos de Cardinal.

Ainda que normalmente classificada como autobiográfica - e sendo, certamente, íntima - a obra de Cardinal não deixa de ser política. Como pied-noir, ela modela em seus livros o sentimento de dupla-identidade cultural. Isso, juntamente com a consciência histórica da ascendência colonizadora, ilustrada nos romances pelo sentimento de culpa, confere à sua obra grande expressão política anticolonial e antipatriarcal. Esse é o segundo interesse predominante em Cardinal.

Com frequência, Cardinal evoca a Argélia como a terra à qual sente apego visceral e na qual está enraizada: sua terra-mãe. Em contrapartida, demonstra desde a infância certa relutância - ou até mesmo desprezo - pelo que a França lhe representa: patriarcalismo, fundamentalismo, hegemonia cultural, colonialismo. Nascida entre aristocratas, Cardinal cresceu atrelada aos privilégios culturais e materiais da elite, mas na vaga liberdade que 
experimentava no caminho de casa até a escola, no contato com a realidade que a cercava, começou a percebê-la. Na ocasião da guerra, já tinha consciência da injustiça e desigualdade do sistema instaurado.

A consciência política de Cardinal é desenvolvida no e pelo quadro político-social francês dos eventos de maio de 1968: "em 68, descobri tudo: as mulheres, a ecologia, o marxismo, o maoísmo" (CARDINAL apud HALL, 1994, p. 9, tradução nossa) ${ }^{2}$. Graças ao movimento, ela que sempre esteve num embate com seu ambiente, regrado por valores burgueses e patriarcais, redescobre-se e transforma-se. A par da alienação cultural do colonialismo, a autora descobre a própria alienação individual como mulher. Ao lado da opressão cultural, a opressão de gênero caracteriza o terceiro interesse - talvez o crucial - da escritura de Cardinal.

Ao encontrar na psicanálise a cura dos problemas psicossomáticos que enfrentava por anos, Cardinal revisita a relação problemática com sua mãe, que personificava o sistema de valores ao qual estava sujeita e que a levou àquele estado de neurose. Descobrindo as origens de seus problemas com a mãe, ela se descobre como mulher e, junto disso, o sistema repressivo que atinge todas as mulheres. Cardinal afirma que foi a mulher de todos os seus livros (CARDINAL, 1977, p. 86) e um traço comum entre suas heroínas é encontrar a escrita na busca por autoconhecimento. Ora, foi justamente no processo de cura pela análise que Cardinal se tornou escritora.

Consciente do sistema que oprime as mulheres, Cardinal percebe que existe um padrão interligando os sistemas opressores que coordenam nossa sociedade. Eis o que ela denuncia em seus livros. Não aceitou o rótulo de "escritora feminista" por acreditar que o movimento feminista, tal como ocorria na França da época, centrava-se demais em questões teóricas e muito afastadas dos problemas reais das mulheres. (HALL, 1994, p. 10)

Cardinal encontra na própria linguagem uma ferramenta de desconstrução do sexismo; ela aborda o elementar da vida da mulher, falando por aquelas que não têm voz, ou que não têm os meios para manifestá-la, devolvendo a possibilidade de expressão de suas experiências únicas com o corpo, com a sexualidade, com o ser e com a matéria. A autora não busca inventar uma escritura feminina, mas uma escritura viva e vivida:

para Cardinal, não se trata de subverter a linguagem estabelecida nem de criar uma linguagem feminina especializada. Inventar uma escritura feminina é sobretudo abrir o sentido das palavras para que elas possam exprimir, sem equívocos, o viver da mulher (HALL, 1994, p.10, tradução nossa) ${ }^{3}$. 
Eis as experiências que modelam Marie Cardinal: o hibridismo cultural, a psicanálise e o maio de 68. Nesse e por esse contexto, seus trabalhos foram de grande pertinência, não apenas para o quadro francês contemporâneo, acompanhando outros nomes relevantes como Hélène Cixous e Simone de Beauvoir, mas para todos os estudos pós-coloniais e, ainda, para a psicanálise internacional.

\subsection{Os caminhos abertos}

Conforme discutido pela crítica de literatura francesa, Hall (1994, 2006), é notória a relevância de Cardinal no sistema francês; sua literatura foi premiada ${ }^{4}$ e recebeu adaptações cinematográficas e teatrais que até hoje circulam na França. Todavia, uma análise da inserção da obra da autora em contextos diversos precisa levar outros fatores em consideração. Iniciemos observando um panorama quantitativo ${ }^{5}$ das traduções de cada uma de suas obras ${ }^{6}$ :

Quadro 1 - Línguas para as quais a Obra Cardinal foi traduzida

\begin{tabular}{|l|l|}
\hline \multicolumn{1}{|c|}{ Quadro 1 - Línguas para as quais a Obra Cardinal foi traduzida } & \multicolumn{1}{c|}{ TRADUÇÃo } \\
\hline Écoutez la mer (1962) & Grego (1985) e italiano (1985). \\
\hline La Mule de corbillard (1963) & Dinamarquês (1984) e grego (1984). \\
\hline La Souricière (1965) & $\begin{array}{l}\text { Alemão (1983), dinamarquês (1980), grego (1985), holandês } \\
\text { (1983), inglês (1983) e italiano (1983). }\end{array}$ \\
\hline Cet été-là (1967) & Inglês (1967). \\
\hline La clé sur la porte (1972) & $\begin{array}{l}\text { Alemão (1980), coreano (1990), dinamarquês (1984), } \\
\text { espanhol (1979), estoniano (1985), grego (1983), inglês (1984) } \\
\text { e italiano (1985). }\end{array}$ \\
\hline Les mots pour le dire (1975) & $\begin{array}{l}\text { Alemão (1977), croata (1985), dinamarquês (1978), espanhol } \\
\text { (1976), finlandês (1981), grego (1977), hebreu (1985), } \\
\text { holandês (1978), inglês (1983), italiano (1975), japonês } \\
\text { (1983), norueguês (1979), polaco (1995), português (1976), } \\
\text { romeno (1995), sérvio (1985) e sueco (1978). }\end{array}$ \\
\hline Autrement dit (1977) & $\begin{array}{l}\text { Dinamarquês (1988), Grego (19--), inglês (1995), italiano } \\
\text { (1982) e sueco (1982). }\end{array}$ \\
\hline Une vie pour deux (1979) & $\begin{array}{l}\text { Alemão (1979), coreano (1980), dinamarquês (1982), } \\
\text { espanhol (1979), grego (1991), italiano (1981) e sueco (1980). }\end{array}$ \\
\hline Au pays de mes racines (1980) & $\begin{array}{l}\text { Alemão (1985), dinamarquês (1982), grego (1982), italiano } \\
\text { (1981) e sueco (1982). }\end{array}$ \\
\hline Le passé empiété (1983) & $\begin{array}{l}\text { Alemão (1984), dinamarquês (1988), espanhol (1983), } \\
\text { finlandês (1984), grego (1983), italiano (1984) e sueco (1983). }\end{array}$ \\
\hline Les grands désordres (1987) & $\begin{array}{l}\text { Alemão (1988), dinamarquês (1988), grego (1988), inglês } \\
\text { (1991), italiano (1988), norueguês (1989), sueco (1988) e } \\
\text { turco (1989). }\end{array}$ \\
\hline Les Pieds-Noirs (1988) & $\begin{array}{l}\text { Alemão (1991), dinamarquês (1991), italiano (1992) e sueco } \\
\text { (1991). }\end{array}$ \\
\hline
\end{tabular}

DIETZE, Maitê. Marie Cardinal Traduzida: A Trajetória internacional de seus escritos. Belas Infiéis, Brasília, v. 9, n. 1, p. 89-108, 2020. 


\begin{tabular}{|l|l|}
\hline $\begin{array}{l}\text { Les jeudis de Charles et Lula } \\
\text { (1994) }\end{array}$ & $\begin{array}{l}\text { Coreano (1999), dinamarquês (1994), grego (1997), italiano } \\
\text { (1997) e sueco (1994). }\end{array}$ \\
\hline Amour...Amours... (1998) & Dinamarquês (2000) e grego (2000). \\
\hline L'Inédit (2012 - póstumo) & \\
\hline
\end{tabular}

Elaboração: Maitê Dietze.

Nota-se que dos dezesseis romances de sua autoria, apenas dois não foram traduzidos; as traduções de Cardinal ultrapassam vinte línguas diferentes. Em destaque, está Les mots pour le dire, o best-seller que vendeu mais de 320 mil cópias só na França e foi traduzido em dezessete línguas - sendo a única obra de Cardinal traduzida em português - dentre essas, apenas cinco traduziram o livro que o sucede, Autrement dit; vale ressaltar que este último também não foi traduzido em português.

Da observação desses dados, despontam questionamentos: por que Autrement dit, se diretamente relacionado a Les mots pour le dire, não adentrou tantos caminhos através de traduções? O que fez com que determinados sistemas literários buscassem a tradução do segundo? Para começar a refletir sobre essas questões, apresento inicialmente as particularidades de Autrement dit e de Les mots pour le dire; depois, atento à recepção de ambas as traduções em inglês, analisando seus paratextos. Finalmente, comento a tradução e o estado da arte no Brasil.

\section{Les mots pour le dire e Autrement Dit}

Em Les mots pour le dire (1975), Cardinal relata o percurso doloroso de uma mulher que, guiada pela psicanálise, segue rumo à cura da doença a qual se refere como "a coisa" (la chose). Essa tal coisa lhe causava um sangramento uterino, semelhante à menstruação, mas imprevisível e incessante, que a impedia de viver: sempre inquieta com a fluência do sangue, só se permitia sair de casa por curtos períodos, vivendo reclusa e refém do próprio sangue. Após recorrer a inúmeros especialistas, sem obter nenhuma melhora, ela procura um psicanalista para uma "pausa" do tratamento psiquiátrico: "Doutor, estou exangue. [...] Isso são problemas psicossomáticos, não me interessam. Fale-me de outra coisa" (CARDINAL, 1975, p. 11, tradução nossa) ${ }^{7}$.

Desde as primeiras palavras ouvidas, ela se vê desmantelada: o sangue, eixo em torno do qual há anos girava sua vida, de agora em diante não importaria mais. Era apenas o véu que precisava cair para que pudesse encarar a realidade de seus problemas. Chorando pesadas lágrimas que há muito não escorriam, aceita o tratamento e suas condições: interromper o uso 
de quaisquer medicamentos, frequentar três sessões por semana e, nestas, falar. Falar tudo, sobre tudo, sem censurar, sem classificar, sem fazer uso dos seus conhecimentos e seus pressupostos terapêuticos.

A psicanálise a impulsiona em busca das palavras para dizer a coisa: exprimir seus medos, seus traumas, sua vida. Abordando a relação com sua mãe, seu sentimento de (não) pertencimento à Argélia e à França, seu embate com o ambiente burguês-patriarcal, o tratamento psicanalítico desvela e descontrói a opressão desses sistemas que a subjugaram a ponto de lhe acarretarem a mais cruel neurose.

O sucesso desse romance foi imenso; contudo, nem mesmo o alto número de vendas poderia mensurar o valor real de Les mots pour le dire. A obra-prima de Cardinal é o raro tipo de texto que toca profunda e diretamente a vida de seus leitores (DUHRAM apudCARDINAL, 1995, p. VIII). Nele, a autora alcança o que se propunha: a expressão real da vida e de suas questões, outrora herméticas, identificando e cativando todos que tiveram o privilégio de conhecê-lo.

Graças à Les mots pour le dire, Cardinal encontra seus leitores em conferências e debates. Autrement dit narra que, na ocasião dessas conferências, Cardinal decidiu elaborar uma subsequência para a obra que lhe possibilitou contatar seu público, proporcionando discussões e reflexões engrandecedoras, tanto sobre sua escrita quanto sobre si mesma. Junto de outra escritora feminista francesa, Annie Leclerc, autora de Parole de femme (1974), Cardinal desenvolve esse trabalho. O livro inicia com o prefácio de Cardinal e é composto por sessões não numeradas - divididas conforme as transcrições dos diálogos das autoras -, intercaladas com descrições de Cardinal. No posfácio, Leclerc registra suas considerações.

Autrement dit exemplifica a escrita cíclica, polifônica e de intergêneros de Cardinal (HALL, 1994, p. 10). Leclerc propõe, nos encontros com Cardinal, questões desencadeadoras por meio das quais elas pudessem divagar sobre diversos assuntos, normalmente entrelaçando os temas comuns da obra de Cardinal: linguagem, escritura, mulheres, Argélia, política, psicanálise, etc. Cardinal escreve o livro baseando-se nessas conversas, nas quais Leclerc inclui seu próprio interesse e guia uma interlocução frutífera. Autobiografia, entrevista, ensaio e ficção, Autrement dit figura a maleabilidade da obra de Cardinal. Nas palavras da autora, “[...] esse livro não é um, é uma reflexão em voz alta, uma conversa com os outros” (CARDINAL, 1977, p. 9, tradução nossa) ${ }^{8}$, o que se assemelha a sessões de psicanálise: “a questão da psicanálise será frequente no decorrer dessas páginas - o que é normal, afinal a psicanálise 
nunca termina, é uma forma de pensar, de levar a vida" (CARDINAL, 1977, p. 12, tradução nossa $)^{9}$.

Cardinal defende a não-classificação dos textos por gêneros. Analisando como fora classificado Les mots pour le dire ${ }^{10}$, conclui que até nesse âmbito impera a supressão da voz feminina:

fica claro que o romance aborda problemas sérios, a questão da vida, da morte, do sonho, da felicidade, da política. Tudo isso em um romance de mulher fácil de ler? Não. Então, não é um romance e nem um ensaio, é um documento sobre psicanálise. Não é literatura, é um depoimento (CARDINAL, 1977, p. 85, tradução nossa) ${ }^{11}$.

Dada a escrita cíclica característica da obra de Cardinal, ambos os livros são entrecruzados pelos três interesses centrais de sua identidade e trabalho. Assim como anuncia a relação com a psicanálise, Cardinal explicita opiniões sobre a França, a Argélia e a colonização:

a França tinha, face à Argélia, um comportamento colonialista que também é chamado de "paternalismo", o câncer do cérebro. [...] Câncer do estômago e do cérebro, câncer generalizado afinal. Estupidez generalizada agravada por uma total falta de politização, trazida pela OAS (Organização Armada Secreta) só no último momento (CARDINAL, 1977, p. 23-24, tradução nossa) ${ }^{12}$.

Se Les mots pour le dire destaca o processo psicanalítico, Autrement dit persegue uma voz feminina para falar dos âmbitos femininos, inexplorados e silenciados - o terceiro dos interesses da obra de Cardinal. Para ela, essa voz não necessita de outra linguagem para ser expressa; a nossa própria linguagem deve ser expandida, e não manipulada ou ornamentada. Elaborando a discussão que iniciara sobre gêneros textuais, Cardinal chega à questão crucial: o apelo à leitura das palavras da mulher de forma plena, independentemente das imposições da linguagem que é instrumento de manutenção do domínio falocêntrico:

acho que é preciso que a crítica e os leitores adquiram o hábito de nos deixar usar as palavras tais quais elas são, sem ter que adicionar ou subtrair um "toque" feminino (e tampouco feminista) quando somos nós, as mulheres, que nos servimos delas. Se vencermos esse combate, poderemos então inventar palavras para preencher as lacunas deixadas na nossa língua por imensos domínios inexprimidos e essenciais, que são todos, por acaso, domínios femininos. Domínios que, no entanto, pertencem à humanidade e o fato de explorá-los deve enriquecer todo mundo, tanto homens quanto mulheres. [...] Hoje em dia, todas as palavras têm dois sentidos, dois sexos, conforme forem empregadas por um homem ou por uma mulher (CARDINAL, 1977, p. 88 , tradução nossa) ${ }^{13}$. 
Essa visão sobre o relativismo das palavras norteia a escritura do texto. Cardinal dá ao leitor as coordenadas de interpretação de sua obra: ela escreve para expandir o sentido das palavras, incorporando a ideia mallarmeliana de preencher as lacunas da língua; por meio disso, torna-se possível que ela, mulher, aproprie-se da linguagem e seja lida como sujeito falante, para que então a linguagem possa expressar a sexualidade, a gestação e o viver da mulher. Eis o discurso que ela representa e que deve ser conduzido na tradução.

\subsection{The words to say it}

Tendo atingido o marco de best-seller na França, Les mots pour le dire é classificado menos como romance e mais como documento sobre psicanálise (cf. nota X). Ora, a notável e particular obra sobre psicanálise desperta o interesse de editores nos cinco continentes. Os leitores anglófonos, todavia, só a encontram em 1983, com a publicação de VanVactor \& Goodheart (editora de Massachusetts), cuja tradução é de Pat Goodheart.

Figura 1 - Capa da editora VanVactor\&GoodHeart

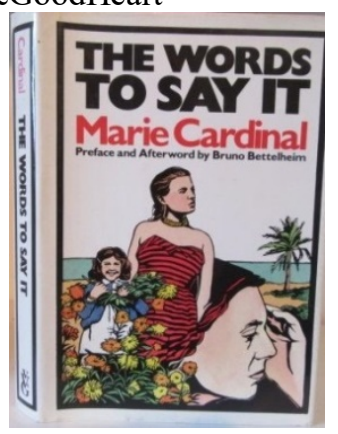

Fonte: Open Library (2019).

Conforme se observa na figura 1 , nessa edição é evidente a escolha editorial de destacar os paratextos assinados pelo renomado psicanalista Bruno Bettelheim. Seus comentários elogiosos sobre o trabalho de Cardinal certamente agregaram grande valor a The words to say it (1983); se o célebre psicanalista foi cativado por esse testemunho, certamente outros leitores o seguiram - já na capa figura o nome de Bettelheim, logo abaixo ao nome da autora. Entretanto, há de se considerar que tal orientação pode extrapolar o intuito de Cardinal nessa produção. Embora relatasse seu tratamento, não é sobre psicanálise que ela escreve; o que ela escreve é um recorte da vida de uma mulher para quem a psicanálise teve grande importância, dialogando com sua própria vida: ela defende que todos escritos são, inevitavelmente, pelo menos em parte autobiográficos (CARDINAL, 1977, p. 86).

Outras editoras publicaram essa tradução junto dos textos de Bettelheim: em 1984, é publicada pela Picador, igualmente informando os paratextos na capa (figura 2). Em 1993, a 
editora londrina Women's Press lança sua edição, sem os paratextos, mas apresentando, na capa, outras informações para guiar a recepção: abaixo da citação elogiosa da atriz Ingrid Bergman, o título The words to say it vem subtitulado por "an autobiographic novel”, (figura 3):

Figura 2 - Capa da editora Picador

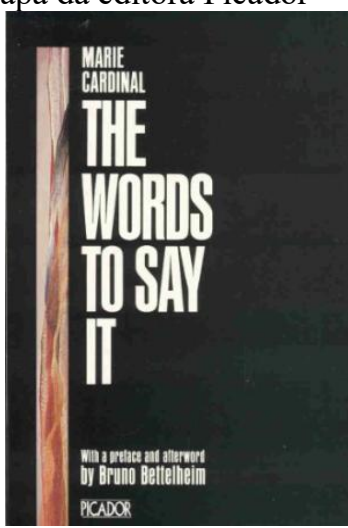

Fonte: Ebay (2019).
Figura 3 - Capa da editora Women's Press

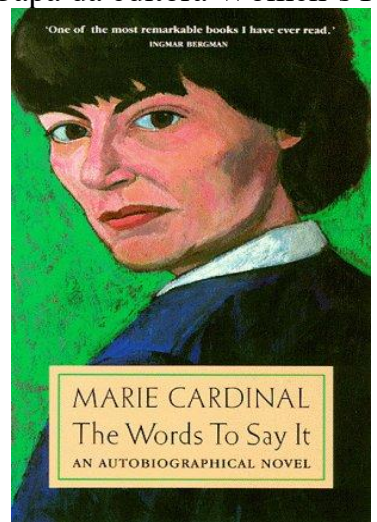

Fonte: AbeBooks (2019).

A informação, já no título, de um gênero textual, indica ao leitor o teor da obra: como supracitado, para a autora sempre há algo de autobiográfico nos textos. Mas, tratando-se da escrita de Cardinal, explícita e intencionalmente nada estática, é arriscado enquadrá-la apenas como romance autobiográfico: a autora opõe-se veementemente a tais leituras restritivas:

não gosto que os livros tenham um gênero definido, gosto que sejam ao mesmo tempo romance, poesia, ensaio, pesquisa, história, filosofia. O que eu quero é que se reconheça que escrevo, mesmo que não escreva livros classicamente de mulheres, “romances de mulher" (CARDINAL, 1977, p. 87-88) ${ }^{14}$.

A grande difusão dessa obra reflete nas proporções das produções críticas ${ }^{15}$ sobre ela. Embora o volume ${ }^{16}$ dos trabalhos acadêmicos e o escopo desse artigo impeçam uma análise no detalhe, uma breve observação dos dados levantados já é elucidativa. Os escritos sobre a tradução em inglês, datando de 1990 e depois, inserem-se em quatro áreas e/ou interdisciplinas. Menos de cinco produções focam nos estudos de tradução (francês-inglês); nos estudos culturais e pós-coloniais, cerca de quinze produções citam o texto na tradução de Pat Goodheart; os números aumentam na crítica literária e feminista, com cinquenta e duas contribuições; somando mais de cento e quarenta textos, a esmagadora maioria de trabalhos referenciando The words to say it (1983) situa-se nas áreas de psicanálise e psicoterapia. 
Gráfico 1 - Recepção acadêmica de The words to say it (1983)

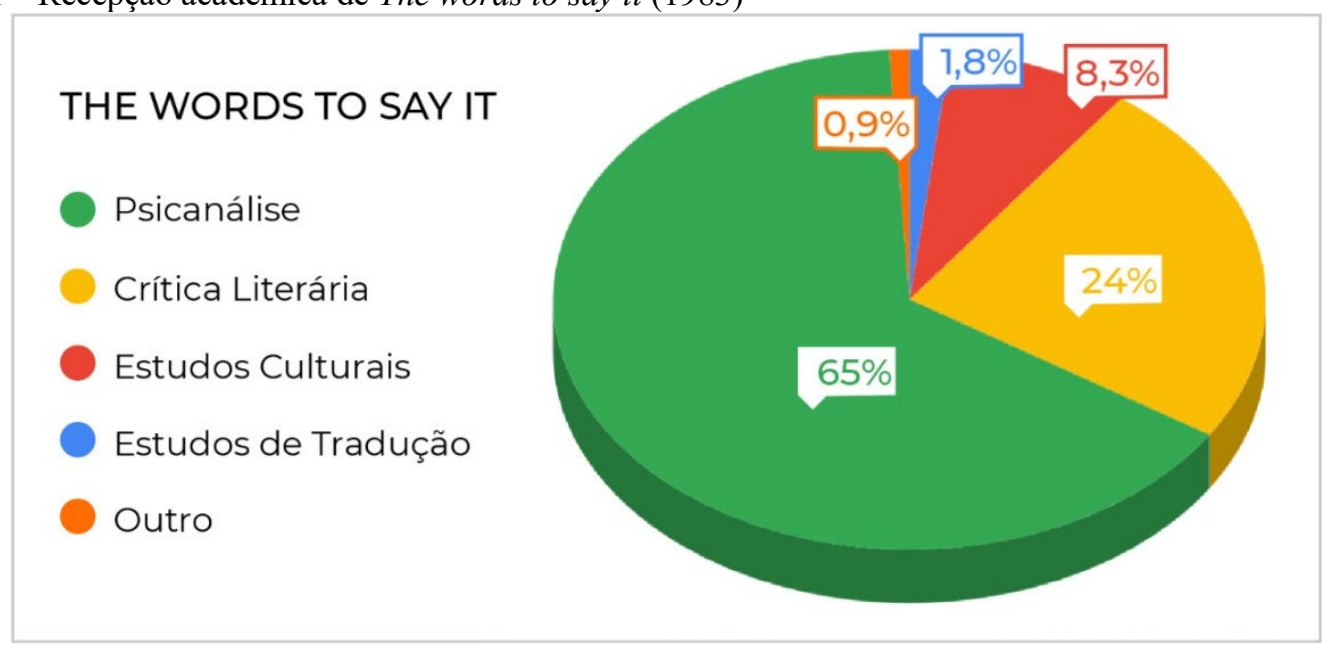

Elaboração: Maitê Dietze.

Essa análise quantitativa sustenta as hipóteses sobre as escolhas editorais das informações e dos paratextos. Realmente, o espaço de recepção de The words to say it foi sobretudo psicanalítico. O mesmo padrão é observado nos trabalhos mais citados: os que contam com mais de cinquenta citações são, decrescentemente, de psicanálise, crítica literária feminista, estudos culturais, de tradução e interdisciplinares (psicanálise e feminismo).

\subsection{In other words}

$\mathrm{O}$ alcance de Autrement dit, tanto na França quanto por traduções, foi inferior a seu predecessor. Dentre os poucos sistemas que o traduziram, o anglófono foi o que recebeu de forma mais positiva. Em 1995, a Indiana University Press publica In other words, traduzido por Amy Cooper, cujo nome aparece na capa do livro (figura 4). Um ano depois, a editora Women's Press publica essa tradução em Londres, indicando na capa se tratar da sequência de The words to say it, mas sem informações sobre a tradutora (figura 5). 
Figura 4 - Capa da editora Indiana University

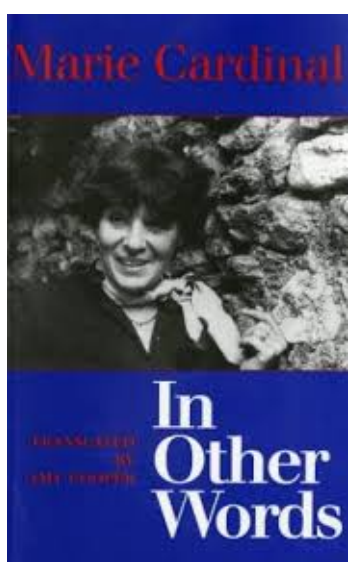

Fonte: Book Depository (2019).
Figura 5 - Capa da Women's Press para In other words

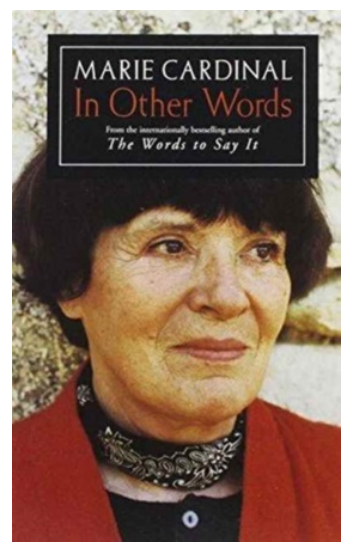

Fonte: Book Depository (2019).

Ao contrário do livro anterior, In other words não é definido quanto ao gênero e tampouco direcionado à psicanálise. Conta com prefácios de Carolyn A. Durham, crítica de literatura francesa feminista, e da tradutora Amy Cooper; o posfácio é de Durham. Assim como os de Bettelheim, cada um desses peritextos é rico e merece análises detalhadas e individuais. Numa tentativa de sintetizar seus méritos, relevo a discussão de Durham sobre a importância da obra de Cardinal para os estudos feministas; ela classifica Cardinal como crucial para o entendimento do feminismo como unificado (DURHAM apud CARDINAL, 1995, p. XIV$\mathrm{XV})$.

De acordo com Durham (1995), na época em que um abismo gigantesco dividia em polos distintos o que seria a corrente feminista "francesa" e a "norte-americana", Cardinal não se identificava com nenhuma, embora fosse inegavelmente feminista. No que tange à temática da escritura feminina, a corrente feminista francesa colocava como centro da discussão o anseio e necessidade de uma linguagem feminina; a norte-americana, por sua vez, voltava-se aos problemas materiais da mulher. A concepção de literatura e linguagem feminina proposta por Cardinal desconstrói essa oposição binária e errônea, defende Durham. Cardinal busca, por meio da própria expansão da linguagem (e não da sua cisão em uma linguagem especializada feminista) tocar as questões da relação da mulher com a matéria. Ainda segundo Durham, além do prejuízo de dividir o movimento, tal dicotomia desconsidera as produções originadas fora desses dois polos, centrando-se em sistemas imperialistas. Cardinal, como sujeito cultural híbrido (BHABHA, 2013), ou seja, aquele que transita entre dois polos culturais distintos, ultrapassa essas distinções engessadas. 
Pouco se escreveu na academia sobre In other words se comparado a The words to say it. Segundo o corpus consultado (cf. nota XV), as citações diretas dessa obra são em: Women, culture and international relations (JABRI; O'GORDMANN, 1999); Inquiry and creative process (MAY, 2005); Nanou gazing across the Mediterranean (CAMPORA, 2017) e Writing out your life (STANLEY, 1998). Nota-se diferenças de números e de temáticas. Vista por lentes da crítica feminista, pelos paratextos de In other words, Marie Cardinal transfere-se da psicologia para adentrar áreas como crítica literária, feminista e cultural.

\section{No Brasil: por onde andou Marie Cardinal?}

A incursão de Cardinal nas terras lusófonas é menos extensa do que nas anglófonas. Contra as seis traduções em inglês, apenas um livro foi traduzido em português brasileiro - Les mots pour le dire. Contudo, essa efêmera visita de Cardinal no sistema brasileiro foi anterior: a primeira edição do livro data de 1976, logo após o lançamento na França. A tradução de Rachel Jardim, intitulada Palavras por dizer (figura 6), foi publicada pela editora carioca, Imago, que, fundada em 1967, entrou no mercado brasileiro com inéditas traduções de Sigmund Freud; 102 atualmente, permanece voltada à psicanálise e às ciências humanas. Ora, não surpreende que essa editora tenha investido em trazer, até o Brasil, Cardinal e seu best-seller "sobre" psicanálise. Entretanto, tal empreitada não obteve resultados positivos como no sistema anglófono; não apenas teve menos difusão crítica, mas também não progrediu para a tradução da sequência, Autrement dit. A editora em questão - por vezes criticada no que tange às traduções e revisões - pode ter tomado decisões que facilitaram essa (não) difusão.

Figura 6 - Capa da editora Imago

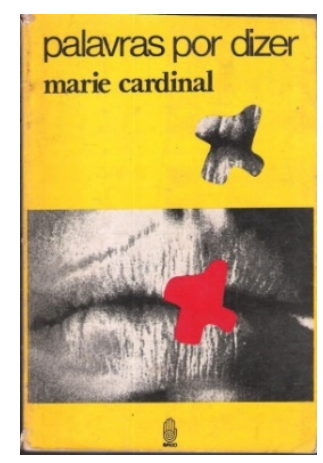

Fonte: Skoob (2018).

Embora não proponha aqui análises prescritivas das traduções per se, é inevitável não comentar os títulos. Les mots pour le dire significa, literalmente, "as palavras para dizê-lo", ou "as palavras para o dizer" (o vocábulo "le" pode funcionar como complemento direto do verbo 
“dire" ou como artigo definido, substantivando o verbo). Dado o conteúdo do texto, o título é esclarecedor: eis o encontro das palavras que expressam algo, a coisa. Em contrapartida, se algo está “por" dizer, como no título em português, a ideia é oposta: algo ficou inexpresso, não dito. Isso, por si só, dá outra face para o livro apresentado: um relato de cura pela palavra torna-se a angústia perante algo que não pode ser exprimido. Considerando que o sucesso de Les mots pour le dire e de The words to say it foi impulsionado pelas leituras psicanalíticas, o enfraquecimento desse apelo possivelmente prejudicou a recepção no Brasil.

O livro tem apenas uma outra edição, de 1990, pela editora Trajetória Cultural (figura 7). Nessa edição, no entanto, a tradução é de Wanda Caldeira Brant. A demanda por outra tradutora para uma nova edição em relativamente curto espaço de tempo é curiosa; em inglês, mesmo havendo mais edições, utiliza-se somente a tradução de Pat Goodheart para The words to say it e de Amy Cooper para In other words.

Figura 7 - Capa da editora Trajetória Cultural

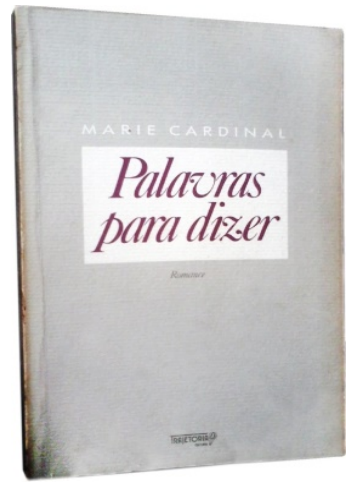

Fonte: Livralivro (2019).

Observando a produção acadêmica brasileira sobre Cardinal presente no corpus consultado, repara-se na divisão entre referências à edição da Imago e à da Trajetória Cultural. Dentre os cinco trabalhos encontrados, três citam a primeira edição: Psicanálise e literatura: Palavras por dizer (MACHADO, 2008); De uma escrita com função de testemunho (REIS, 2010); Clínica na atualidade (ABREU; SILVA, 2012). Citando a segunda, temos: Morte e vida da palavra em 'Palavras para dizer' (ADAMO, 2015) e Um alto monte (REGO, 1996). Todos tangendo a psicanálise, revela-se que a recepção das obras em português foi inferior em quantidade e interdisciplinaridade, se comparada à anglófona. 


\section{Considerações finais}

Embora a literatura francesa seja repleta de escritoras feministas de prestígio, Cardinal parece ocupar um lugar de destaque, sobretudo graças a sua posição particular e enriquecedora no que tange à relação entre as feministas francesas e norte-americanas da época (DURHAM apud CARDINAL, 1995, p. XIV). Sua capacidade de encontrar na própria linguagem as palavras para expressar com harmonia o hermetismo da vida, da psique e da matéria, engaja leitores e críticos. Essa complexidade torna seu trabalho inclassificável; Cardinal não toma as questões psíquicas como distintas das questões de ser mulher, e tampouco as distingue das culturais. Aborda-as dinamicamente em um todo emaranhado que não tem começo ou fim. Não é possível encaixar a obra de Cardinal apenas em uma temática ou gênero: isso é bem aceito na crítica acadêmica, contudo, muitas vezes o mercado editorial investe em tentativas frustradas de classificação única.

A maturidade com que trata problemáticas culturais, de gênero e da alma é percebida até nos sistemas literários distantes, que a aproximam de sua cultura por meio de traduções. Perante tal escrita singular, a tarefa da tradução em outras línguas torna-se ainda mais complexa.

Não por acaso que, nos exemplos analisados, foram observadas divergências na transposição dessa maleabilidade: enquanto a academia recebe The words to say it principalmente no âmbito da psicanálise, In other words destaca-se entre os estudos feministas. As duas traduções brasileiras do primeiro, entretanto, são pouco citadas em trabalhos acadêmicos do corpus consultado, havendo citação direta à Cardinal apenas em cinco textos, e a sequência sequer possui tradução. A relativa debilidade na recepção de ambas as edições pela academia, se comparadas com a recepção das edições anglófonas, pode ser resultante de diversos fatores, desde escolhas editoriais atenuantes até questões mercadológicas.

A viagem de Cardinal por terras brasileiras ainda precisa ser ampliada, sendo mais traduzida e melhor estudada. Detentora de complexidade e, ao mesmo tempo, fluidez intelectual e sensível, há muito que explorar nela e com ela para o ganho do sistema literário brasileiro. Nessa contribuição, apresentaram-se alguns dos méritos de Cardinal e sua trajetória internacional, detendo-se em casos significativos para elucidação do estado da arte no sistema literário brasileiro.

A complexidade de trabalho de Cardinal e a riqueza de cada uma das traduções aqui apresentadas exigem pesquisas subsequentes para aprofundar as análises, por exemplo: de um lado, dos paratextos de Bettelheim para a tradução em inglês de The words to say it e da recepção pela psicanálise e, de outro, dos paratextos de Durham para a tradução de In other 
words e a crítica feminista. Tratar a questão da recepção da sua literatura, o modo como esta adentrou determinado sistema literário, em seus contextos socioculturais específicos, pode ser muito revelador sobre como foi lida, inclusive pelos tradutores. Ademais, seria imprescindível estender a análise das traduções anglófonas ao nível microestrutural. Para as próximas pesquisas sobre Cardinal no Brasil, será interessante cotejar as duas traduções em português de Les mots pour le dire e, principalmente, traduzir Autrement dit será fundamental para a revitalização da contribuição de Cardinal na literatura, feminismo, estudos culturais e psicanálise.

\section{REFERÊNCIAS}

ABEBOOKS. Imagem. 2019. Disponível em: https://pictures.abebooks.com/isbn/9780704343467-us.jpg. Acesso em: 26 set. 2019.

ABREU, K. H. SILVA, A. S. A clínica na atualidade. Saúde mental em foco, v. 1, n. 1, p. 119 ago. 2012. Disponível em:

http://ojs.cesuca.edu.br/index.php/saudementalemfoco/article/view/21. Acesso em: 24 set. 2019.

ADAMO. V.L. Morte e vida da palavra em Palavras para dizer. Ide, v. 37, n. 59, São Paulo, fev. 2015. Disponível em:

http://pepsic.bvsalud.org/scielo.php?script=sci_arttext\&pid=S0101-31062015000100005 Acesso em: dez. 2019.

BHABHA, H. K. O local da cultura. 2. ed. Traduzido por: Myriam Ávila, Eliana Lourenço de Lima Reis e Gláucia Renate Gonçalves. Belo Horizonte: Ed. UFMG, 2013. Tradução de: The location of culture.

BOOK DEPOSITORY. Imagem. 2019. Disponível em:

https://d1w7fb2mkkr3kw.cloudfront.net/assets/images/book/lrg/9780/2532/9780253209924.j pg. Acesso em: 24 mar. 2019.

BOOK DEPOSITORY. Imagem. 2019. Disponível em: https://d1w7fb2mkkr3kw.cloudfront.net/assets/images/book/lrg/9780/7043/9780704345034.j pg. Acesso em: 24 set. 2019.

CAMPORA, C. M. Nanou gazing across the Mediterranean: A journey through space, memory and nostalgerie. 2017. Dissertação. (Master of Arts Thesis). University of California, Los Angeles, 2017. Disponível em: https://escholarship.org/uc/item/4kv3n0cq Acesso em: dez. 2019.

CARDINAL, M. Autrement dit. Paris: Grasset, 1977.

CARDINAL, M. Les Grands Désordres. Paris: Grasset, 1987. 
CARDINAL, M. Les Pieds-Noirs. Paris: Belfond, 1988.

CARDINAL, M. La Souricière. Paris: Julliard, 1963.

CARDINAL, M. Amour...Amours... Paris: Grasset, 1998.

CARDINAL, M. Au pays de mes racines. Paris: Grasset, 1980.

CARDINAL, M. Cet été-là. Paris: Julliard, 1967.

CARDINAL, M. Comme si de rien n'était. Paris: Grasset, 1990.

CARDINAL, M. Écoutez la mer. Paris: Julliard, 1962.

CARDINAL, M. In other words. Traduzido por: Amy Cooper. Bloomington: Indiana University Press, 1995. Tradução de: Autrement dit.

CARDINAL, M. L’inédit. Paris: Grasset \& Annika Parance, 2013.

CARDINAL, M. La Clé sur la porte. Paris: Grasset, 1972.

CARDINAL, M. La Mule et le corbillard. Paris: Julliard, 1963.

CARDINAL, M. Le Passé empiété. Paris: Grasset, 1983.

CARDINAL, M. Les Jeudis de Charles et Lula. Paris: Grasset, 1994.

CARDINAL, M. Les Mots pour le dire. Paris: Grasset, 1975.

CARDINAL, M. Palavras para dizer. Traduzido por: Wanda Caldeira Brant. São Paulo: Trajetória Cultural, 1990. Tradução de: Les mots pour le dire.

CARDINAL, M. Palavras por dizer. Traduzido por: Rachel Jardim. Rio de Janeiro: Imago, 1976. Tradução de: Les mots pour le dire.

CARDINAL, M. The Words to Say It. Traduzido por: Pat Goodheart. Cambridge: Van Vactor \& Goodheart, 1983. Tradução de: Les mots pour le dire.

CARDINAL, M. Une vie pour deux. Paris: Grasset, 1979.

EBAY. Imagem. 2019. Disponível em:

https://i.ebayimg.com/images/g/mDgAAOSw dhcrfoQ/s-1500.jpg. Acesso em: dez. 2019.

DURHAM, C. Prefácio. In: CARDINAL, M. In Other Words. Traduzido por Amy Cooper.

Bloomington: Indiana University Press, 1995, p. VIII-XXII. Tradução de: Autrement dit.

GÉNETTE, G. Seuils. Paris: Seuil, 1987.

HALL, C. Marie Cardinal. Amsterdã: Rodopi, 1994. 
HALL, C. Marie Cardinal's legacy : Quels mots pour la dire ? In: WEBB, E. (org). Marie Cardinal: New perspectives. Oxford: Peter Lang, 2006, p. 227-250.

JABRI, V. O'GORDMAN, E. Women, culture and international relations. Boulder: Lynne Rienner, 1999.

LAMBERT, J.; VAN GORP, H. V. On Describing Translations. In: The Manipulation of Literature. Studies in Literary Translation. London \& Sidney: Croom Helm, 1985, p. 4253.

LECLERC, A. Parole de femme. Paris: Grasset, 1974.

LIVRALIVRO. Imagem. 2019. Disponível em:

https://livralivro.com.br/uploads/book/img/129/8585232129.jpg. Acesso em: dez. 2019.

MACHADO, I.D. Psicanálise e literatura: Palavras por dizer (Marie Cardinal). Ágora Instituto Lacaniano, 2008. Disponível em:

http://agorainsti.dominiotemporario.com/doc/Palavras_por_dizer_ISLO.pdf. Acesso em: dez. 2019.

MAY, V. Intuitive inquiry and creative process: a case study of na artistic practice.

Dissertação. (Master of Arts Thesis). Queensland University of Technology, Brisbane, 2005. OPEN LIBRARY. Imagem. 2019. Disponível em:

https://ia800708.us.archive.org/view_archive.php?archive=/33/items/olcovers657/olcovers65 7-L.zip\&file=6576604-L.jpg\&ext=. Acesso em: dez. 2019.

REGO, R.A. Um alto monte. In: Reichiana 5. Instituto Sede Sapientiae, São Paulo, 1996, p. 83-102.

REIS, M.G.P. De uma escrita com função de testemunho: abordagem psicanalítica da transmissão da experiência. Dissertação (Dissertação em Psicologia Social). Universidade Federal do Rio Grande do Sul, Porto Alegre, 2010.

SKOOB. Palavras por dizer. Imagem. 2018. Disponível em:

https://cache.skoob.com.br/local/images//q677n0nRmkj4_W9KaHk8fZ8oI5U=/202x312/cent er/top/smart/filters:format(jpeg)/https://skoob.s3.amazonaws.com/livros/63836/PALAVRAS_ POR_DIZER_1285366901B.jpg. Acesso em: dez. 2019.

STANLEY, J. Writing out your life: a guide to writing creative autobiography. Fort Worth: Scarlet Press, 1998.

\footnotetext{
* Maitê DIETZE - Mestranda em Estudos da Tradução pela Universidade Federal de Santa Catarina. Graduada (2018) em Letras - Tradução Português/Francês pela Universidade Federal do Rio Grande do Sul. Bolsista CAPES-DS. Florianópolis, Santa Catarina, Brasil.

Currículo acadêmico: http://lattes.cnpq.br/8442681746503888

ORCID: https://orcid.org/0000-0001-8390-1645

E-mail:mait_@hotmail.com

${ }^{1}$ Prix international du premier roman.

2 “En 68, j'ai tout découvert, les femmes, l'écologie, le marxisme, le maoïsme
} 
3“Il ne s'agit pas pour Cardinal de bouleverser le langage établi ou de créer un langage spécialisé-femme. Inventer une écriture feminine, c'est plutôt ouvrir les mots pour leur permettre d'exprimer, sans équivoque, le vécu des femmes". Todas as traduções citadas no artigo são da autora.

${ }^{4}$ Écoutez la mer (1962): Prix International du Premier Roman. Les mots pour le dire (1975) : Prix Littré.

${ }^{5}$ Dados de WorldCat. Disponível em: http://www.worldcat.org. Acesso em: 3 dez. 2018.

${ }^{6}$ A tabela não inclui as traduções realizadas por Cardinal. São elas: La Médée d'Euripide (1986); Peer Gynt d'Henrik Ibsen (1991); Les Troyennes d'Euripide (1993) e Edipe à Colone de Sophocle (2003).

7 “-Docteur, je suis exsangué. [...] -Ce sont des troubles psychosomatiques, cela ne m'intéresse pas. Parlez-moi d'autre chose". (CARDINAL, 1975, p. 11)

8 “[...] ce livre n'en est pas un, il est une réflexion à voix haute, une conversation avec les autres". (CARDINAL, 1977, p. 9)

9 “De la psychanalyse il sera souvent question au cours de ces pages. C'est normal, une psychanalyse ne se termine jamais, c'est une façon de penser, de prendre la vie". (CARDINAL, 1977, p. 12)

${ }^{10}$ Cardinal questiona por que seu livro foi classificado primeiramente na seção "romances", mas, quando alcançou o marco de best-seller, passou para "Ensaios e Documentos" (CARDINAL, 1977, p. 85-86).

11 "Il est clair que des problèmes graves y sont abordés, qu'il y est question de la vie, de la mort, du rêve, du bohneur, de la politique. Tout ça dans un roman de femme qui se lit facilement? Non. Ce n'est donc ni un roman ni un essai, c'est un document sur la psychanalyse. Ce n'est pas de la littérature, c'est un témoignage". (CARDINAL, 1977, p. 85)

12 “La France avait, vis-à-vis de l'Algérie française, un comportement colonialiste qu'on appelera aussi le paternalisme, ce cancer du cerveau. Cancer du ventre et du cerveau, cancer généralisé donc. Bêtise généralisée compliquée d'une absence totale de politisation ce qui, au dernier moment, donera l'O.A.S'. (CARDINAL, 1977, p. 23-24)

13 “'Je crois qu'il faut que la critique et les lecteurs prennent l'habitude de nous laisser utiliser les mots tels qu'ils sont, sans leur ajouter ou leur retrancher une "touche" féminine (et encore moins féministe) quand c'est nous, les femmes, qui nous en servons. Si nous gagnons ce combat nous pourrons ensuite inventer des mots pour boucher les espaces laissés vides dans notre langue par d'immenses domaines inexprimés et essentiels qui sont tous, comme par hasard, des domaines féminins. Des domaines qui appartiennent d'ailleurs à l'humanité et le fait de les occuper doit enrichir tout le monde, les hommes comme les femmes. À l'heure actuelle tous les mots ont deux sens, deux sexes, selon qu'ils sont employés par un homme ou par une femme". (CARDINAL, 1977, p. 88)

14 “'Je n'aime pas que les livres aient un genre défini, j'aime qu'ils soient à la fois roman, poésie, essai, recherche, histoire, philosophie. Ce que je veux c'est qu'on reconnaisse que j'écris même si je n'écris pas des livres classiques de femmes, 'des romans de femmes"'. (CARDINAL, 1977, p. 87-88)

15 As consultas realizadas para o presente artigo foram feitas a partir de pesquisas do nome da autora no corpus das bases de dados do Google Acadêmico, Érudit e Scielo. Acesso em: 3 dez. 2018.

${ }^{16}$ Foram encontrados cerca de 230 trabalhos que referenciam diretamente The words to say it (1983). 